\begin{tabular}{|l|l|}
\hline $\begin{array}{l}\text { 2. To: (Recolving Organization) } \\
\text { DISTRIBIJ' } 1 \text { ON }\end{array}$ & $\begin{array}{l}\text { 3. From: (Originating Organization) } \\
\text { INTERIM STABILIZATION }\end{array}$ \\
\hline $\begin{array}{l}\text { 5. Proj./Prog/Dept./Div.: } \\
\text { INTERIM :'I'ABILIZATION }\end{array}$ & $\begin{array}{l}\text { 6. Design Authority/Design Agent/Cog. Engr.: } \\
\text { W. E. ZUROFF }\end{array}$ \\
\hline
\end{tabular}

\section{Originator Remarks:}

ATTACH(i) [S AN ACCEPTANCE TEST PLAN (ATP) FOR THE NEW PUMPING INSTRUMI:NTATION AND CONTROL (PIC) SKIDS BEING FABRICATED BY SITE FABRICNIIION SERVICES.

4. Related EDT No.:

$\mathrm{N} / \mathrm{A}$

7. Purchase Order No.

$\mathrm{N} / \mathrm{A}$

9. Equip./Component No:

$\mathrm{N} / \mathrm{A}$

10. System/Bidg./Facility:

241-G

12. Major Assm. Dwg. No.:

$\mathrm{N} / \mathrm{A}$

13. Permit/Permit Application No.:

$\mathrm{N} / \mathrm{A}$

14. Required Response Date:

NONE

11A. Design Baseline Document? $\bigotimes$ Yes $\square$ No
$05 / 26 / 2000$

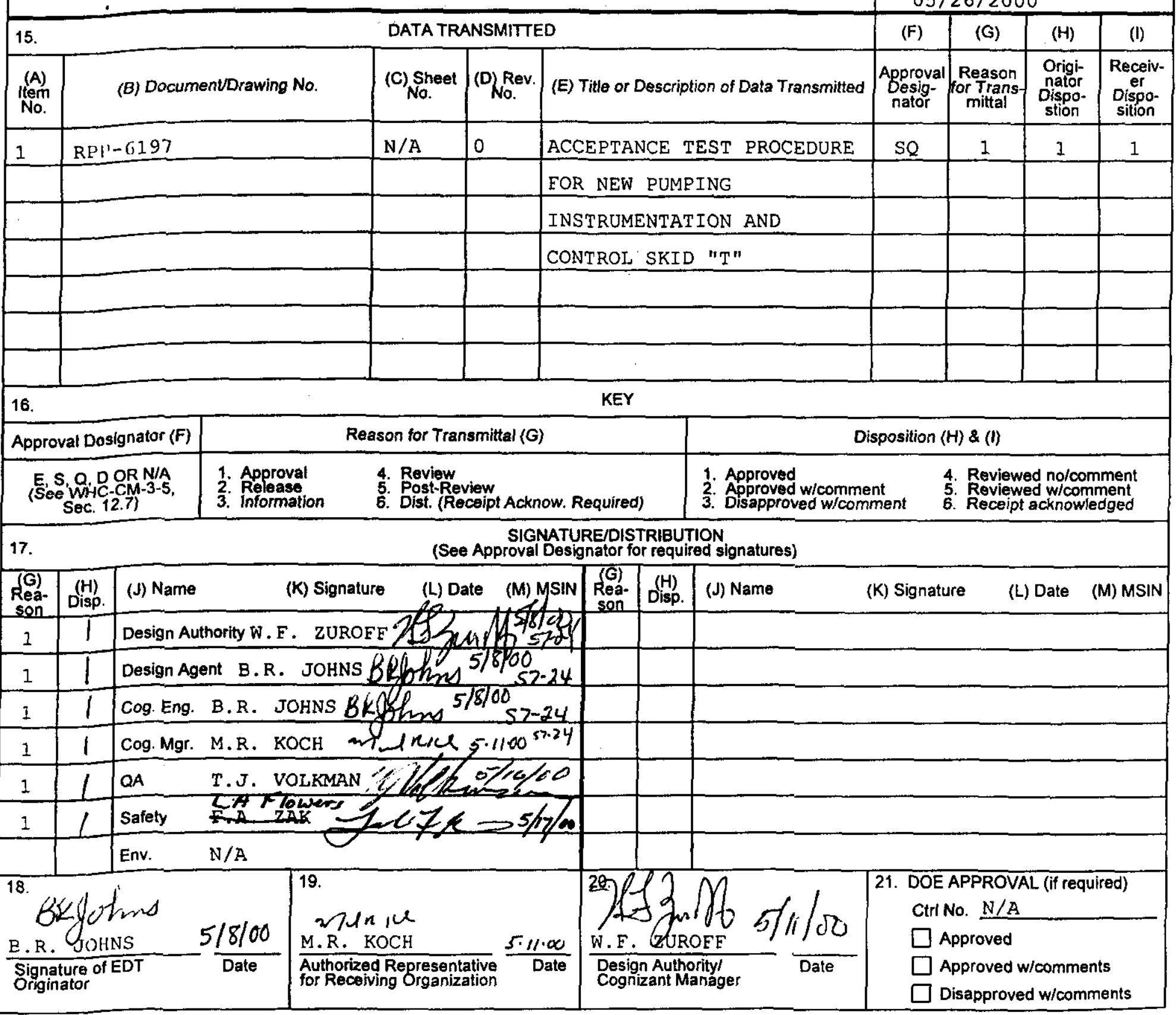




\title{
ACCEPTANCE TEST PROCEDURE FOR NEW PUMPING INSTRUMENTATION AND CONTROL SKID "T"
}

\author{
M. R. $100 \mathrm{CH}$ \\ CH2MHILL HAWFORD GROUP, INC \\ Richland, WA 90852 \\ U.S. Department of Eneroy Contract DE-AC06-99RL14047
}
EDT/ECN: 624922 UC:
Cost Center: 74D00 Charge Code: 103361
B\&R Code: EW3120071 Total Pageš: g't

$\therefore{ }^{4}:$

Key Words: PICS, SALT WELI, SKID, INTERIM STABILIZATION, ACCEPTANCE TEST

\begin{abstract}
:
This Acceptance Test Procedure (ATP) provides for the inspection and testing of the new Pumping Insstrumentation and Control (PIC) skid designed as "T". The ATP will be performed after the construction of the PIC skid in the fabrication shop.
\end{abstract}

\section{$\therefore$}

TRADEMARK DlecuAmER. Rofwrence herein to any specfic commercial product, process, or service by trade name,

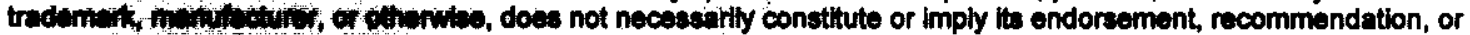

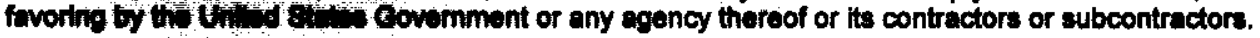

Printed in the Unthed stintes of Amorice. To obtain copies of this document, contact: Document Control Services, P.O. Box 950, Mallitop H8-08, Plichlend WA 99352, Phone (509) 372-2420; Fax (509) 376-4989.

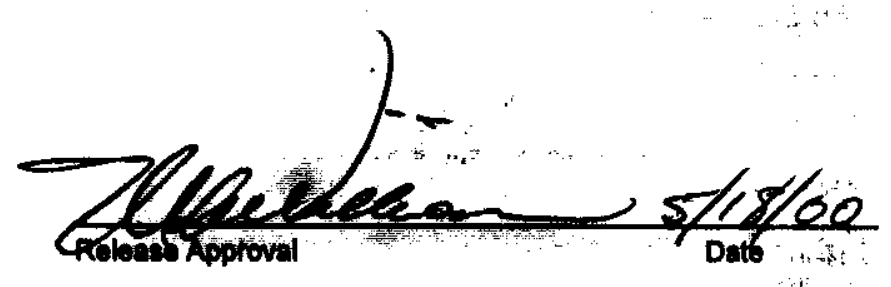

Approved For Public Release

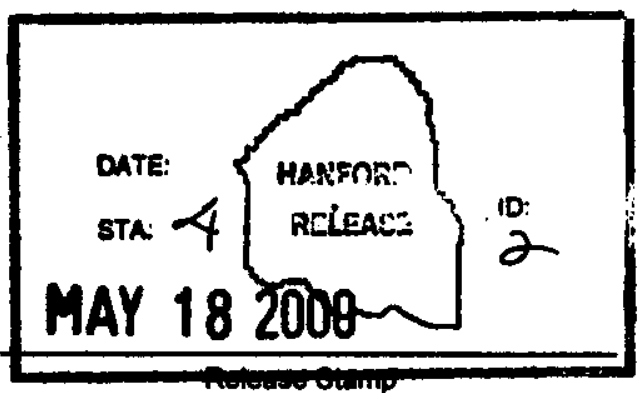

urup 


\section{TABLE OF CONTENTS}

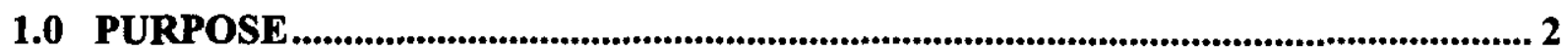

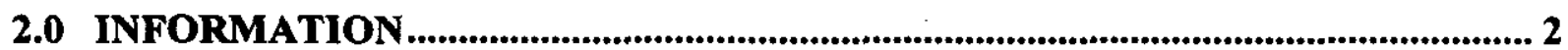

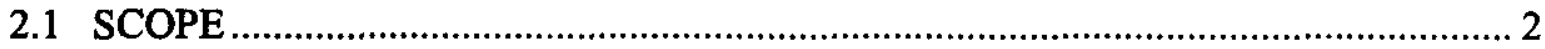

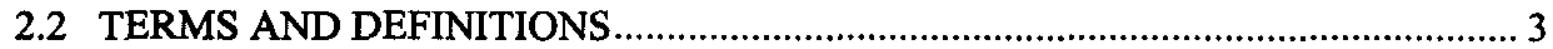

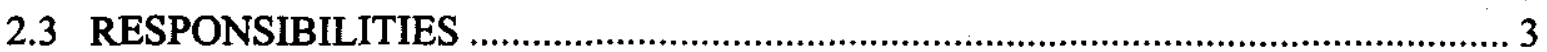

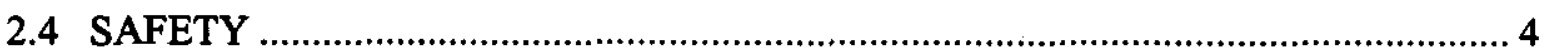

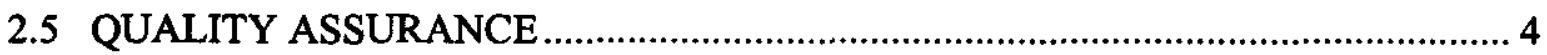

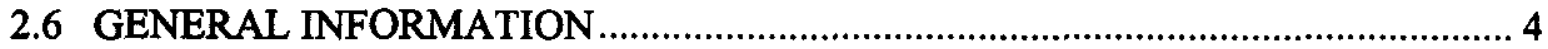

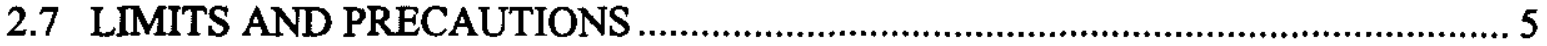

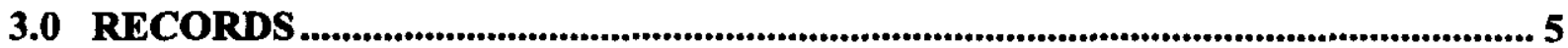

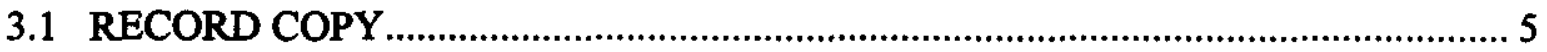

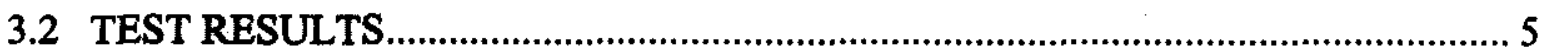

4.0 PREREQUISITES ............................................................................................................................. 6

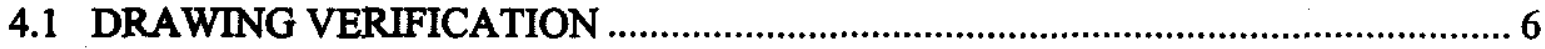

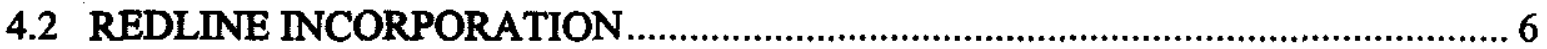

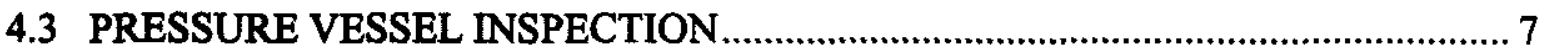

4.4 NATIONAL ELECTRICAL CODE (NEC) INSPECTION ………........................ 7

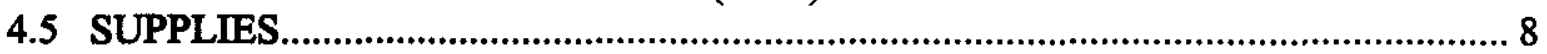

4.6 PRESTART CONDITIONS …….................................................................... 10

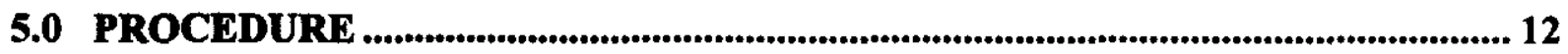

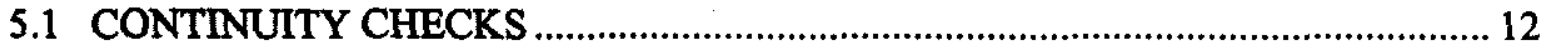

5.2 MEGGERING OF POWER WIRES .................................................................. 14

5.3 ELECTRICAL POWER CHECKS ………….............................................. 16

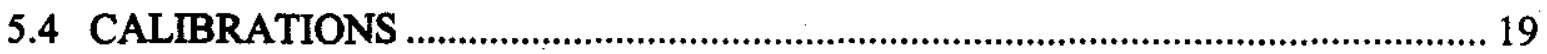

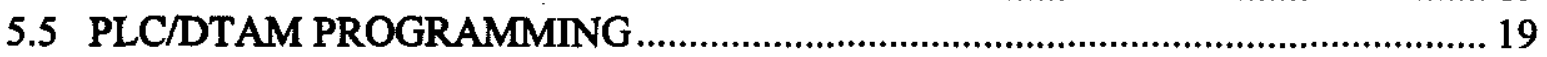

5.6 SKID ELECTRICAL AND PROCESS AIR POWER-UP ………………………... 20

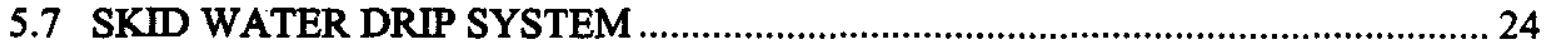

5.8 INPUT SIGNALS TO THE PLC AND DTAM ................................................... 26

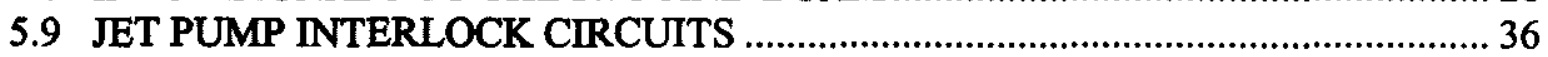

5.10 HEATERS, AIR CONDITIONER AND LIGHTS ………............................ 46

5.11 SKID PREPARATION FOR SHIPPING ..................................................... 48 
RPP-6197

REVISION 0

\section{ACCEPTANCE TEST PROCEDURE FOR NEW PUMPING INSTRUMENTATION AND CONTROL SKID “T”}

\subsection{PURPOSE}

This Acceptance Test Procedure (ATP) verifies proper construction per the design drawings and tests for proper functioning of the Pumping Instrumentation and Control (PIC) skid " $T$ ". The scope section lists the systems and functions to be checked. This ATP will be performed at the Site Fabrication Services (SFS) shop upon completion of the construction of the PIC skid.

\subsection{INFORMATION}

\subsection{SCOPE}

This Acceptance Test Procedure verifies and/or tests the following items or systems:

2.1.1 Drawing verification (Prerequisites)

2.1.2 Red-line incorporation

2.1.3 Code Inspections (Prerequisites)

2.1.4 Instrument calibrations

2.1.5 Continuity, megger and voltage checks

2.1.6 Programmable Logic Controller (PLC) and Data Table Access Module (DTAM) programming

2.1.7 Air system

2.1.8 Water system

2.1.9 PLC inputs and outputs

2.1.10 Alarms and interlocks

2.1.11 Heaters, air conditioner and lights 


\section{$2.2 \quad$ TERMS AND DEFINITIONS}
2.2.1 DOV - Diaphragm Operated Valve
2.2.2 GPM - Gallons Per Minute
2.2.3 IA - Instrument Air
2.2.4 LDE - Leak Detector Element
2.2.5 PRV - Pressure Relief Valve
2.2.6 SGT - Specific Gravity Transmitter
2.2.7 WFT - Weight Factor Transmitter
2.2.8 LT - Level Transmitter
2.2.9 WFIE - Weight Factor Instrument Enclosure
2.2.10 PLC - Programmable Logic Controller
2.2.11 DTAM - Data Table Access Module
2.2.12 PSPT - Pump Suction Pressure Transducer
2.2.13 PDPT - Pump Discharge Pressure Transducer
2.2.14 PXPT - Pump Transfer Pressure Transducer
2.2.15 JFPT - Jumper Flush Pressure Transducer
2.2.16 RFPT - Recirculation Flush Pressure Transducer
2.2.17 PIC - Person In Charge

\subsection{RESPONSIBILITIES}

2.3.1 CHG Quality Assurance is responsible for:

2.3.1.1 Witnessing and signing steps as identified in the Acceptance Test Procedure.

2.3.1.2 Verifying that the ATP sections were performed correctly.

2.3.1.3 Approving Exception resolution and exception closure.

2.3.2 Test Engineer (or representative) and/or PIC are responsible for:

2.3.2.1 Identifying the equipment required for the ATP.

2.3.2.2 Recording equipment status and data per this ATP.

2.3.2.3 Conducting pre-job system walk-down.

2.3.2.4 Recording data and other notes during the ATP performance.

2.3.2.5 Providing technical support during the ATP.

2.3.2.6 Providing PLC/DTAM programming support during the ATP.

2.3.2.7 Acting as Test Director during the ATP.

2.3.2.8 Approving Exception resolution and exception closure. 


\subsection{SAFETY}

Warning: 120vac energized circuits and leads may be encountered during testing when accessing PLC input/output terminals. Observe appropriate electrical precautions as directed by RPP-PRO-088, Electrical Work Safety.

Warning: Cabinets on the PIC skid contain circuits energized with 480vac and 120vac. Comply with RPP-PRO-088, Electrical Work Safety.

\subsection{QUALITY ASSURANCE}

CHG Quality Assurance Inspector is to ensure that testing is performed per this ATP document. The Quality Assurance Inspector shall sign and date each ATP section verifying the data obtained and that the section was performed correctly.

\subsection{GENERAL INFORMATION}

2.6.1 All data entries recorded in this procedure shall be made in black or blue ink.

2.6.2 Editorial changes required to this ATP shall be made by redlining the affected section by the engineer as long as the changes do not impact the personnel safety or the technical aspects of this ATP. These changes shall be recorded on the ATP log sheet.

2.6.3 Unexpected results during testing shall be logged in the Acceptance Test Procedure "Exception Log" and documented on an Acceptance Test Procedure "Exception Record."

2.6.4 Technical changes to this ATP shall be logged as "Exceptions and documented on the "Exception Record."

2.6.5 Do not perform any part of this ATP on faulty equipment. If faulty equipment is discovered, STOP the execution of that section of the ATP and resolve the problem OR continue with another section until the problem is repaired.

2.6.6 If the performance of the ATP is suspended for any reason, ensure the equipment is left in a safe condition per the direction of the test engineer and/or PIC and any Lock and Tag system requirements are met before leaving the test site.

2.6.7 This ATP DOES NOT contain separate data/verification sheets. Verification of the ATP steps and validity of data is recorded in this ATP next to each step as required.

2.6.8 A Job Hazard Analysis for shall be used in conjunction with the Pre-job safety meeting form when any unusual hazards are identified. The Pre-job meeting form (attached to this ATP) shall be used to document all attendees. NOTE: No unusual hazards are expected during the performance of this ATP.

2.6.9 An ATP log shall be used to record comments concerning the ATP performance such as each day's testing activities. 
2.6.10 The engineer or PIC may deviate from test steps if necessary to ensure safe equipment configuration during testing or suspension of testing. Configuration shall be noted so the equipment may be restored at the resumption of testing.

2.6.11 Alarms may be acknowledged during testing at the direction of the test engineer or PIC if specific instructions are not given in the test steps.

2.6.12 Sections 4.2, 4.3, 4.4, 5.4 and 5.5 can be performed out of sequence in order to facilitate the completion of this ATP.

2.6.13 Sections 5.8 through 5.10 can be performed out of order as directed by the test engineer and/or PIC as necessary to facilitate ATP performance.

2.6.14 All personnel performing, initialing and/or signing this ATP shall enter their signature and initials on the Procedure Performer Signature Sheet on the last page of this document.

\subsection{LIMITS AND PRECAUTIONS}

NONE

\subsection{RECORDS}

\subsection{RECORD COPY}

The record copy of this ATP when completed shall be kept with the fabrication work package.

\subsection{TEST RESULTS}

A test report, RPP-6198 shall be issued with the final test results upon completion of this ATP. 
RPP-6197

REVISION 0

\subsection{PREREQUISITES}

\subsection{DRAWING VERIFICATION}

A check of the constructed skid is to be compared to either the redlined drawings or the final unreleased skid drawings. Engineering shall verify the accuracy of the essential and support drawings. Engineering shall determine a resolution for all discrepancies by either correcting the drawings or changing the equipment.

The following drawings shall be walked down for verification of proper construction of the skid:

4.1.1 Wire terminations and wiring labels on drawings $\mathrm{H}-14-103812$, sheets 7 through 12 and $\mathrm{H}-14-103815$, sheet 5.

4.1.2 Panel board arrangement on drawing H-14-103818.

4.1.3 Flow diagram on drawing H-14-103817.

Drawing verification completed. (Final drawing release is not required to continue with this ATP.)

Engineer Signature Date

\subsection{REDLINE INCORPORATION}

4.2.1 Ensure the relines identified on the construction drawings in the fabrication work package are incorporated on the final drawings for skid " $T$ " prior to the drawings being released. NOTE: Redlines must meet the intent of the markups and may not be exactly the same in order to meet drafting standards or for clarity.

4.2.2 Engineer to verify the redline incorporation is completed by signing below. 


\subsection{PRESSURE VESSEL INSPECTION}

A pressure vessel inspection by a third party inspector is required for the air compressor receiver tank and relief valves located in the air compressor cabinet and the water tank and relief valves located in the water cabinet. The inspection is to verify that the equipment meets National Codes for pressure vessels. An outside-certified inspector shall perform this inspection. (This inspection shall be completed prior to testing the air compressor and water systems.)

Pressure vessel inspection report received. (The ATP can continue before the report is received, but must be received prior to performing sections 5.6 and 5.7.)

Report \#'s: (Inspection \#'s on tanks)

\section{Engineer Signature Date}

Information has been supplied to the PMS database to add relief valve inspection for the air compressor and water tanks. Completion of the database update will be tracked by the Acceptance for Beneficial Use documentation.

Engineer Signature Date

\subsection{NATIONAL ELECTRICAL CODE (NEC) INSPECTION}

4.4.1 An NEC inspection shall be performed to verify compliance to NFPA 70, latest version.

4.4.2 Areas in particular to be inspected are the 480vac and 120vac wiring and grounding.

4.4.3 An NEC inspection sticker is to be placed on the inside or the outside of the panel board door upon the NEC inspector's acceptance of the electrical portion of the skid.

The NEC inspection sticker is placed on the panel board door. (This needs to be completed prior to the section 5.0 functional checks.) Report \# (from sticker)

Engineer Signature Date 
RPP-6197

REVISION 0

\subsection{SUPPLIES}

The following supplies are required for this ATP. NOTE: Test sections may commence prior to assembly of all the test equipment. Engineer and/or PIC are to ensure test equipment is available prior to the start of each section.

4.5.1 Volt/ohm meter (VOM): Portable, 0-600vac

Calibration No. Exp. Date QA

Calibration No. Exp. Date QA

Calibration No. Exp. Date QA

\subsubsection{Transmation current (milliamp) simulator or equivalent}

Calibration No. Exp. Date QA

Calibration No. Exp. Date QA

Calibration No. Exp. Date QA

Calibration No. Exp. Date QA

Calibration No. Exp. Date QA

4.5.3 Manometer capable of a minimum of 5 inches water gauge to a maximum of 125 inches water gauge for this ATP and a read-out of variable test pressure.

Calibration No. Exp. Date QA

Calibration No. Exp. Date QA

Calibration No. Exp. Date QA

4.5.4 Megaohm meter, at least 500vac range.

Calibration No. Exp. Date QA

\subsubsection{Temperature simulator capable of 100 to 150 degrees $F$.}

Calibration No. Exp. Date QA

Calibration No. Exp. Date QA 

$480 \mathrm{vac}, 3$ phase, 30 -ampere power supply for PIC skid.

Selector switches ( 3 each) with at least one contact.

4.5.8_ Proximity switches (for simulating LS-1 and LS-2), 2 each.

4.5.9 L Leak detector probes ( 2 each) not required to be green tagged.

4.5 .10 Heat gun to warm thermocouple probes.

pump and jumper.

4.5.12_Buckets or pans for water for leak detector test and catching water from DIP tubes and relief valves.

4.5.13 Water supply and hose to fill water tank.

4.5.14 I _ Ice water or cold air spray to cool thermocouple probes. 


\subsection{PRESTART CONDITIONS}

4.6.1___ Fill the water tank at least one-third to half full of water. Operate the appropriate valves in the water cabinet to accomplish this task.

4.6.2_ Ensure the PIC skid is grounded in preparation for ATP testing.

4.6.3 Ensure the following PIC skid valves in the WFIE cabinet are OPEN prior to starting this ATP.

NOTE: All valves, electrical equipment and instruments are prefixed with "SALW".

V-6035T (EQUALIZING)
V-6036T (EQUALIZING)

4.6.4 Ensure the following PIC skid valves are CLOSED prior to starting this ATP.

Air Compressor Cabinet

Water Cabinet

$\mathrm{V}-6025 \mathrm{~T}$
$\mathrm{~V}-6026 \mathrm{~T}$
$\mathrm{~V}-6034 \mathrm{~T}$
$\mathrm{~V}-6043 \mathrm{~T}$
$\mathrm{~V}-6044 \mathrm{~T}$
$\mathrm{~V}-6046 \mathrm{~T}$
$\mathrm{~V}-6047 \mathrm{~T}$
$\mathrm{~V}-6048 \mathrm{~T}$
$\mathrm{~V}-6049 \mathrm{~T}$
$\mathrm{~V}-6050 \mathrm{~T}$
$\mathrm{~V}-6051 \mathrm{~T}$
$\mathrm{~V}-6053 \mathrm{~T}$

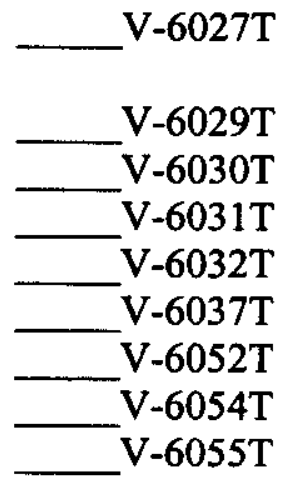

WFIE Cabinet

$\mathrm{V}-6001 \mathrm{~T}$
$\mathrm{~V}-6002 \mathrm{~T}$
$\mathrm{~V}-6003 \mathrm{~T}$
$\mathrm{~V}-6004 \mathrm{~T}$
$\mathrm{~V}-6005 \mathrm{~T}$
$\mathrm{~V}-6006 \mathrm{~T}$
$\mathrm{~V}-6007 \mathrm{~T}$
$\mathrm{~V}-6008 \mathrm{~T}$
$\mathrm{~V}-6011 \mathrm{~T}$
$\mathrm{~V}-6012 \mathrm{~T}$
$\mathrm{~V}-6013 \mathrm{~T}$
$\mathrm{~V}-6014 \mathrm{~T}$

\begin{tabular}{c} 
V-6015T \\
V-6016T \\
V-6017T \\
V-6018T \\
V-6019T \\
V-6020T \\
V-6021T \\
\hline V-6035T(LOW) \\
\hline V-6035T(HIGH) \\
\hline V-6036T(LOW) \\
\hline V-6036T(HIGH) \\
V-6056T
\end{tabular}


RPP-6197

REVISION 0

4.6.5___Ensure the following PIC skid circuit disconnects, breakers and fuses are OPEN or OFF prior to starting this ATP.

DS-6002T

DS-6004T
DS-6003T

DS-6005T

(The following breakers are located in distribution panel DP-6001T.)

\begin{tabular}{c} 
Breaker "MAIN" \\
\hline Breaker 1 \\
Breaker 3 \\
Breaker 5 \\
\hline Breaker 7 \\
Breaker 9 \\
\hline Breaker 11 \\
\hline Breaker 13
\end{tabular}

Breaker 2

Breaker 4

Breaker 6

Breaker 8

Breaker 10

Breaker 12

Breaker 14

(The following fuses are located in the Instrument Enclosure.)

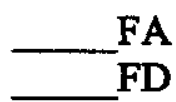

FA

FB

LD

FC

HT

4.6.6 Check for loose electrical connections at the following locations:

Terminal boards in the Instrument Enclosure.

Motor starters and disconnect switches.

Terminal board in junction box inside the WFIE cabinet.

Terminal board in heat trace splice box outside WFIE cabinet.

Terminal board in junction box for FGM outside WFIE cabinet.

Distribution panel board.

4.6.7 Ensure desiccant and filters are installed in the air compressor dryer and filters prior to performing sections 5.6 and 5.7.

4.6.8_Ensure check valves in the air compressor and water cabinet are installed in the proper direction. Reference H-14-103810, sheets 1 and 2.

4.6.9

A pre-job safety meeting shall be held prior to performing section 5.0. Attendees shall sign the Pre-job Brief Signature and Performer Signature pages at the back of this document. 


\subsection{PROCEDURE}

\section{$5.1 \quad$ CONTINUITY CHECKS}

Continuity checks shall be performed with a calibrated VOM. Perform the checks as identified below. Readings are to be less than $1 \mathrm{ohm}$. Record ohm readings on the line(s) provided. Out of tolerance readings must be corrected and rechecked prior to going to the next section. NOTE: NEC inspection must be completed prior to proceeding with this section.

NOTE: All valves, electrical equipment and instruments labels are prefixed with "SALW".

5.1.1 480vac main power plug to the line side of the main disconnect switch (DS$6002 \mathrm{~T})$. Check all three phases and ground.

(RED) (YELLOW) (BLUE) (GND)

5.1.2 Load side of main disconnect switch (DS-6002T) to the line side of transformer disconnect switch (DS-6003T). Check the two phases used and ground. (RED) (YELLOW OR BLUE) (GND)

5.1.3 Load side of main disconnect switch (DS-6002T) to the line side of the jet pump motor starter (DS-6005T). Check all three phases and ground. (YELLOW) (BLUE) (GND)

5.1.4 Load side of main disconnect switch (DS-6002T) to the line side of the air compressor motor starter (DS-6004T). Check all three phases and ground. (RED) (YELLOW) (BLUE) (GND)

5.1.5 Load side of the transformer disconnect switch (DS-6003T) through the primary of the transformer (XFMR-6001T). Check between the two phase wires going to the transformer.

Continuity through the transformer primary. 


\section{RPP-6197 \\ REVISION 0}

5.1.6 Line side of the main breaker in panel board (DP-6001T) through the secondary of transformer (XFMR-6001T). Check between the two phases and between each phase and neutral going to the transformer secondary.

Phase A to phase $\mathrm{C}$, continuity through transformer secondary.

Phase A to neutral, continuity through transformer secondary.

Phase $\mathrm{C}$ to neutral, continuity through transformer secondary.

5.1.7 Load side of breakers in distribution panel (DP-6001T) to terminal point identified.

Circuit 3 to TB10 in Instrument Enclosure (CKT3-H, CKT3-N) Circuit 5 to TB13 in Instrument Enclosure (CKT5H, CKT5N) Circuit 12 to Air Conditioner/Heater receptacle in Instrument Enclosure Circuit 6 to safe side terminal block in Intrinsic Safe panel Circuit 1 to terminal block in FGM power junction box Circuit 11 to terminal block in FGM power junction box Circuit 13 to terminal block in FGM power junction box Circuit 14 to terminal block in FGM power junction box Circuit 2 to terminal block in FGM heat trace splice box Circuit 10 to terminal block in FGM heat trace splice box Circuit 4 to receptacle in air compressor cabinet Circuit 7 to receptacles in WFIE cabinet Circuit 8 to receptacle in water cabinet Circuit 9 to outside receptacle below panel board

5.1.8 Section 5.1 completed and all recorded readings within tolerance.

Quality Assurance Inspector Signature

Date 
RPP-6197

REVISION 0

\subsection{MEGGERING OF POWER WIRES}

The power wires shall be checked for resistance to ground and phase to phase. A 500-volt megger shall be used for this check. Minimum acceptable readings are greater than 1000 megaohm or infinity. Test the circuits listed below. Record readings on the lines provided. Out of tolerance readings must be corrected and rechecked prior to going to the next section.

5.2.1 Each of the three phases at the pins of the power plug to ground and phase to phase. (Ensure main disconnect DS-6002T is OPEN.)
A-GND
; B-GND
; C-GND
; A-B
; A-C

B-C

5.2.2 Each of the three phases at the load side of the main disconnect switch (DS$6002 \mathrm{~T}$ ) to ground and phase to phase. (Ensure switches DS-6003T, DS$6004 \mathrm{~T}$ and DS-6005T are OPEN.)
A-GND
; B-GND
; C-GND
; A-B ; A-C

B-C

5.2.3 Each of the two phases on the load side of the transformer disconnect switch (DS-6003T) to ground.
A-GND ; B-GND

5.2.4 Each of the three phases on the load side of the air compressor motor to ground.
A-GND
B-GND
; C-GND

5.2 .5 Disconnect the neutral at the distribution panel from ground.

5.2.6 Each of the two phases and neutral to ground at the distribution panel. A-GND ; B-GND ; NEUTRAL-GND Reconnect the neutral back to ground at the distribution panel.

5.2.8_Disconnect the circuit 6 wire at the safe side terminal block in the Intrinsic Safe panel. light.

Disconnect the circuit 5 wire at TB13 for the Instrument Enclosure 
5.2.10___Ensure all the heaters, lights and air conditioner are disconnected or unplugged from the 120vac circuits. Ensure the fan thermostat switch in the air compressor cabinet is set high enough for the switch contacts to be open.

5.2.11 Megger each of the 14 circuits from the load side of the breaker or from the wire disconnected at the load side of the breaker to ground in the distribution panel.

NOTE: Disconnect each wire from the load side of the breaker on all the ground fault breakers prior to performing the megger check. This will prevent damage to the ground fault circuitry in the breaker. Reconnect the wire after meggering.

CKT \#1 to GND
CKT \#3 to GND
CKT \#5 to GND
CKT \#7 to GND
CKT \#9 to GND
CKT \#11 to GND
CKT \#13 to GND

CKT \#2 to GND CKT \#4 to GND CKT \#6 to GND CKT \#8 to GND CKT \#10 to GND CKT \#12 to GND CKT \#14 to GND

5.2.12 Ensure the load-side wire at each breaker where disconnected is reconnected.

5.2.13_Reconnect the circuit 6 wire to the safe side terminal block in the Intrinsic safe panel.

5.2.14___ Reconnect the circuit 5 wire at TB13 for the Instrument Enclosure light.

5.2.15___ Reconnect any wires disconnected in step 5.2.10 above. (Unplugged items do not have to be plugged back in.)

5.2.16 Section 5.2 completed and all recorded readings are within tolerance. 


\subsection{ELECTRICAL POWER CHECKS}

The voltage checks are to verify proper voltages throughout the skid at specific termination points. Voltages checked are $480 \mathrm{vac}, 3$ phase; 120vac, single phase; $24 \mathrm{vdc}$; and $32 \mathrm{vdc}$. Out of tolerance readings must be corrected when found before going to the next step in this section.

5.3.1 Ensure that all electrical connections are completed. Wires lifted during meggering checks are to be reconnected.

5.3.2 Ensure all switches and breakers are open and the six fuses in the Instrument Enclosure are open.

5.3.3 Ensure all the fuses are installed in the two safety switches (DS-6002T and DS-6003T) and motor starters (DS-6004T and DS-6005T) including the control transformer fuses.

5.3.4 Connect the main power plug on the skid to a three phase, 480vac power source. Source is to be protected by no greater than a 30 ampere over current protection device.

5.3.5_Turn ON the power source to the skid.

5.3.6 Ensure 480vac +/-20vac on the line side of the main disconnect switch (DS-6002T). Record the voltage readings.

vac, A-B

A-C B-C

5.3.7___ Close the main disconnect switch (DS-6002T).

5.3.8_Ensure 480vac $+/-20 \mathrm{vac}$ on the line side of the transformer disconnect $\overline{\text { switch }}$ (DS-6003T). Record the voltage readings.

vac

5.3.9 Ensure 480vac $+/-20 \mathrm{vac}$ on the line side of the air compressor motor starter (DS-6004T). Record the voltage readings.

vac, A-B

vac, $\mathrm{A}-\mathrm{C}$

B-C

5.3.10 Ensure 480vac $+/-20 \mathrm{vac}$ on the line side of the pump motor starter (DS$\overline{6005 T}$ ). Record the voltage readings.

vac, A-B

vac, A-C

B-C 
5.3.11___ Ensure the dead front on the panel board (DP-6001T) is removed for access to the main breaker for a voltage measurement.

5.3.12___ Close the transformer disconnect switch (DS-6003T).

5.3.13 Check for $240 \mathrm{vac}+/-20 \mathrm{vac}$ on the line side of the main breaker. Record the voltage reading. vac

5.3 .14 Open the transformer disconnect switch (DS-6003T).

5.3.15 Replace the dead front on the panel board (DP-6001T).

5.3.16 Close the transformer disconnect switch (DS-6003T).

5.3.17 Close the 100 ampere main breaker in the panel board (DP-6001T).

5.3.18 Check the voltages for the circuits at the locations designated. Record the voltages in the space provided.

\begin{tabular}{|c|l|l|l|l|}
\hline CKT \# & \multicolumn{1}{|c|}{ Check voltage at } & $\begin{array}{c}\text { Bkr Open voltage } \\
\text { (appr. 0vac) }\end{array}$ & $\begin{array}{c}\text { Bkr Closed voltage } \\
(120+/-10 \mathrm{vac})\end{array}$ & $\begin{array}{c}\text { Open } \\
\text { Bkr }\end{array}$ \\
\hline 1 & FGM JUNCTION BOX & & & \\
\hline 2 & FGM HT BOX & & & \\
\hline 3 & TB10, INSTR ENCL & & & \\
\hline 4 & RCPT, AIR COMPR & & & \\
\hline 5 & TB13, INSTR ENCL & & & \\
\hline 6 & TB, INTRINSIC PNL & & & \\
\hline 7 & RCPT, WFIE CAB. & & & \\
\hline 8 & RCPT, WATER CAB. & & & \\
\hline 9 & OUTSIDE RCPT & & & \\
\hline 10 & FGM HT BOX & & & \\
\hline 11 & FGM JUNCTION BOX & & & \\
\hline 12 & RCPT, INSTR ENCL & & & \\
\hline 13 & FGM JUNCTION BOX & & & \\
\hline 14 & FGM JUNCTION BOX & & & \\
\hline
\end{tabular}




\section{RPP-6197}

REVISION 0

5.3.19__ Ensure fuses FA, FB, FC, FD, LD, and HT are installed in the fuseholders and the fuse switches are closed in the Instrument Enclosure. Close breakers 2, 3 and 5 in the distribution panel (DP-6001T).

5.3.21 Ensure $120 \mathrm{vac}+/-10 \mathrm{vac}$ on the load side at the following fuseholders.

FA vac; FB vac; FC vac;

FD vac; (LD) vac; (HT) vac.

5.3.22 Ensure $24 \mathrm{vdc}+/-2 \mathrm{vdc}$ at the $24 \mathrm{volt}$ power supply. vdc. Close breaker 6 in the distribution panel (DP-6001T).

5.3.24_Ensure 32vdc +0/-4vdc at the output of the 3991 power supply in the Intrinsic safe panel (terminals 3 and 4). NOTE: Low voltage reading may indicate the 240/120vac input power switch on the side of the 3991 supply is in the wrong position.) VDC Open breakers 2, 3, 5, and 6 in the panel board (DP-6001T). Open the 100 ampere main breaker in the panel board (DP-6001T). Open the transformer disconnect switch (DS-6003T).

5.3 .28 Open the main disconnect switch (DS-6002T).

5.3.29 Voltage checks completed and readings within tolerance.

Quality Assurance Inspector Signature Date




\subsection{CALIBRATIONS}

Instrumentation equipment on the skid requires calibration prior to the functional testing. Engineering will verify the calibration completion by checking for current calibration stickers on the equipment and checking off the completed calibrations in the table below.

\begin{tabular}{|l|l|l|}
\hline \multicolumn{1}{|c|}{ INSTRUMENT } & \multicolumn{1}{c|}{ LOCATION } & CAL. STICKER ON \\
\hline SALW-PS-6004T & AIR COMPR. CABINET & \\
\hline SALW-WFT-6002T & WFIE CABINET & \\
\hline SALW-LT-6003T & WATER CABINET & \\
\hline SALW-SGT-6001T & WFIE CABINET & \\
\hline SALW-CONV-6001T & WFIE CABINET & \\
\hline SALW-FQIT-6001T & INSTRUMENT ENCL. & \\
\hline SALW-PI-6006T & AIR COMPR. CABINET & \\
\hline SALW-PI-6007T & AIR COMPR. CABINET & \\
\hline SALW-PI-6008T & WATER CABINET & \\
\hline SALW-PI-6001T & WFIE CABINET & \\
\hline SALW-PI-6002T & WFIE CABINET & \\
\hline SALW-PI-6003T & WFIE CABINET & \\
\hline SALW-PI-6004T & WFIE CABINET & \\
\hline SALW-PI-6005T & WFIE CABINET & \\
\hline SALW-PI-6011T & INSTRUMENT ENCL. & \\
\hline SALW-PI-6012T & INSTRUMENT ENCL. & \\
\hline
\end{tabular}

Calibrations completed. Work package nos.

Engineer Signature Date

\subsection{PLC/DTAM PROGRAMMING}

This section is where the programs for the PLC and DTAM will be entered into the equipment. Power will be required (circuit 5) at the Instrument enclosure to power up the PLC and DTAM and for the GFCI receptacle. Engineering will program the equipment from a laptop computer. Final software programs shall be documented as required by HNF-5034. This documentation is not part of this ATP, but will be documented after the OTP in a software report document.

PLC/DTAM programmed. 


\subsection{SKID ELECTRICAL AND PROCESS AIR POWER-UP}

NOTE: The pressure vessel inspection report must be received prior to proceeding with this section. Refer to section 4.3. Ensure desiccant is in the air dryer and the filters installed.

5.6.1__ Ensure the skid is connected to the 480vac power source and grounded before proceeding with this functional test.

5.6.2_Energize or ensure energized the PIC skid by CLOSING the following disconnect switches in the order listed below.

DS-6002T

DS-6003T

DS-6004T

DS-6005T

5.6.3 Energize or ensure energized the breakers in the panel board (DP$\overline{6001 T}$ ).

\begin{tabular}{ll} 
Breaker "MAIN" & Breaker 1 \\
\hline$\quad$ Breaker 3 \\
\hline Breaker 5 \\
\hline Breaker 7 \\
\hline Breaker 9 \\
\hline Breaker 11 \\
\hline$\quad$ Breaker 13
\end{tabular}

Breaker 2 Breaker 4 Breaker 6 Breaker 8 Breaker 10 Breaker 12 Breaker 14

5.6 .4 ACKNOWLEDGE any initial skid alarms.

5.6.5 OPEN valves V-6034T, V-6050T, and V-6053T in the Air compressor cabinet. START the air compressor by positioning the positioning the switch on DS-6004T to the ON position.

5.6.7_Ensure the air compressor starts and builds up pressure and shuts off at 86 to 94 psig as indicated by pressure gauge PI-6006T. RECORD the shut off pressure: psig. test to visually identify any air leaks. Repair as necessary. Deenergize the compressor motor and bleed off air as necessary to make repairs. 
BLEED off air by slowly opening valve V-6043T until the compressor restarts and note the restart pressure as read on gauge PI-6006T. CLOSE valve V-6043T when the compressor restarts. RECORD the restart pressure reading: psig. ENSURE the compressor restarts between 58 to $62 \mathrm{psig}$.

5.6.11 Valve in air to the PIC skid water tank by performing the following steps.

5.6.12 Check for air leaks as each of the remaining steps in this section are performed. SLOWLY OPEN valve V-6025T located in the air compressor cabinet. SLOWLY OPEN valve V-6027T located near the water tank. SLOWLY OPEN valve V-6052T located near the water tank

5.6.16 ADJUST pressure regulator valve PCV-6006T to 30psi (+/-3psi) as indicated by pressure gauge PI-6008T on the outside of the water cabinet. psi

5.6.17 ACTUATE the lever on relief valve PRV-6004T on the top of the air compressor tank and hold open approximately 5 seconds. (Air system is to be at full pressure of approximately $90 \mathrm{psi}$.)

5.6.18_ENSURE the relief valve PRV-6004T seats properly when the lever is released.

5.6.19

ACTUATE the lever on relief valve PRV-6005T on the top of the water tank and hold open approximately 5 seconds. (Water system air pressure is to be at full pressure of approximately $30 \mathrm{psi}$.)

5.6.20_ENSURE the relief valve PRV-6005T seats properly when the lever is released.

5.6.21 VALVE IN air to the WFIE cabinet by performing the following steps.

5.6.22__ SLOWLY OPEN valves_ V-6051T located inside the air compressor cabinet and _ V $-6026 \mathrm{~T}$ located on the outside of the air compressor cabinet.

5.6.23 SLOWLY OPEN valve V-6001T located in the WFIE cabinet. (NOTE: PRV-6002T may open if pressure through PCV-6001T is too high.) 
5.6.24_ADJUST pressure control valve PCV-6001T in the WFIE cabinet to 20 psi $(+/-2.5 p s i)$ as indicated by the pressure gauge located on the face of the valve. SLOWLY OPEN valve V-6004T located in the WFIE cabinet. SLOWLY OPEN valve V-6003T located in the WFIE cabinet. SLOWLY OPEN valve V-6005T located in the WFIE cabinet. SLOWLY OPEN valve V-6006T located in the WFIE cabinet. SLOWLY OPEN valve V-6007T located in the WFIE cabinet. SLOWLY OPEN valve V-6020T located in the WFIE cabinet. SLOWLY OPEN valve V-6021T located in the WFIE cabinet. SLOWLY OPEN valve V-6019T located in the WFIE cabinet.

5.6.33 ADJUST the air flow through the diptubes by performing the following steps.

NOTE: Ensure the DIP tubes are not capped on the outside of the WFIE cabinet when performing steps 5.6.34 through 5.6.36. FIV-6002T. FIV-6003T.

5.6.36_ADJUST flow to dip tube to $1.5 \mathrm{CFH}(+/-0.5 \mathrm{CFH})$ as indicated by FIV-6004T.

5.6.37___ENSURE air flow from pressure regulator PCV-6007T by slowly opening valve $\mathrm{V}-6044 \mathrm{~T}$ in the air compressor cabinet and then reclose the valve.

5.6.38___ ENSURE air flow from pressure regulator PCV-6008T by slowly opening valve $\mathrm{V}-6048 \mathrm{~T}$ in the air compressor cabinet and then reclose the valve. by slowly opening valve V-6046T in the air compressor cabinet and then reclose the valve. 
RPP-6197

REVISION 0

5.6.40 ENSURE air flow from the drain line by slowly opening valves V6047T and V-6046T in the air compressor cabinet and then reclose the two valves.

5.6.41 Engineer to ENSURE section 5.6 is completed and sign below.

Engineer Signature Date

5.6.42 Quality Assurance Inspector to VERIFY that section 5.6 is complete and sign below.

Quality Assurance Inspector Signature

Date 


\subsection{SKID WATER DRIP SYSTEM}

5.7.1_ PROVIDE a container to capture water expelled from the dip tubes and the pressure relief valve PRV-6001T on the outside of the WFIE cabinet.

5.7.2 ACTUATE the Dip Tube Drip system by SLOWLY OPENING the following valves in the WFIE cabinet:

$\begin{array}{r}\mathrm{V}-6016 \mathrm{~T} \\ -\quad \mathrm{V}-6013 \mathrm{~T} \\ \hline \mathrm{V}-6008 \mathrm{~T}\end{array}$

CAUTION: Relief valve PRV-6001T will actuate and relieve pressure at 25psig. SLOWLY OPEN V-6018T WHILE CAREFULLY ADJUSTING Pressure Regulator PCV-6005T located in the WFIE cabinet to 20psig (+/$2 \mathrm{psig}$ ) as indicated on gauge PI-6001T in the WFIE cabinet. psig

5.7 .4 ADJUST valve V-6014T to allow approximately 2 drops/second as indicated by sight glass FG-6001T.

5.7.5 ADJUST valve V-6015T to allow approximately 2 drops/second as indicated by sight glass FG-6002T.

5.7.6 OPEN valve V-6056T very slightly to verify water flow from the "Water Supply to Remote Drip Control" port located on the outside of the WFIE cabinet, then CLOSE valve V-6056T when water is observed.

5.7.7 VALVE OUT the dip tube drip system by SLOWLY CLOSING or ENSURING CLOSED the following valves located in the WFIE cabinet.

$\begin{array}{r}\mathrm{V}-6015 \mathrm{~T} \\ \mathrm{~V}-6014 \mathrm{~T} \\ \mathrm{~V}-6008 \mathrm{~T} \\ \mathrm{~V}-6013 \mathrm{~T} \\ \mathrm{~V}-6019 \mathrm{~T} \\ \mathrm{~V}-6021 \mathrm{~T} \\ \hline \mathrm{V}-6020 \mathrm{~T} \\ \mathrm{~V}-6007 \mathrm{~T} \\ \hline \mathrm{V}-6006 \mathrm{~T} \\ \hline \mathrm{V}-6005 \mathrm{~T}\end{array}$


RPP-6197

REVISION 0

5.7.8 Engineer to ENSURE section 5.7 is completed and sign below.

Engineer Signature Date

5.7.9 Quality Assurance Inspector to VERIFY that section 5.7 is complete and sign below.

Quality Assurance Inspector Signature Date 


\subsection{INPUT SIGNALS TO THE PLC AND DTAM}

5.8.1_ENSURE the two leak detector probes are connected to the skid at the Instrument Enclosure.

5.8.2 ENSURE a normally closed switch is connected to "CGM-AX" and "CKT5H-A" on terminal board TB4 in the Instrument Enclosure. (Can leave existing wires connected.)

5.8.3 ENSURE a normally closed switch is connected to "CGM-F" and "CKT 5H-A" on terminal board TB4 in the Instrument Enclosure. (Can leave existing wires connected.)

5.8.4 ENSURE a normally closed switch is connected to "DIL-F" and "CKT5H-A" on terminal board TB4 in the Instrument Enclosure.

5.8.5 ENSURE two proximity switches are connected to the intrinsic safe terminal block in the Intrinsic Safe panel. Connect a normally closed proximity switch temporarily labeled as LS-1 to "LS-1(+) and LS-1(-)" and a normally open proximity switch temporarily labeled as LS-2 to "LS-2(+) and LS-2(-)". ACTUATE the proximity switches by placing metal in front the switch faces.

5.8.6 ENSURE the DIP switches for the Pepperl-Fuch module in the Intrinsic Safe panel are set to the correct positions: S1 and S2 in position II; and S3 in position I.

\section{WATER TANK LEVEL TRANSMITTER} ENSURE valve V-6031T located in the water cabinet is CLOSED. CONNECT a test manometer pressure source that can output at least 62" water gauge to the HIGH PRESSURE vent/test port of level transmitter LT-6003T.

5.8.10_ENSURE the LOW PRESSURE vent/test port of level transmitter LT$\overline{6003 T}$ is OPEN to atmosphere.

5.8.11 ADJUST the test manometer connected to LT-6003T to a pressure of 31 "water gauge $(+/-1$ "). Record reading 
5.8.12 RECORD the water tank level reading on the DTAM. $31^{\prime \prime}$

5.8.13 The next step will cause a low water level alarm on the DTAM.

5.8.14 VERY SLOWLY DECREASE the test manometer pressure until the "PIC WATER LEVEL LOW" (alarm 9) occurs on the DTAM. (This alarm should occur at 12.25 " $+/-0.5$ " water gauge.)

5.8 .15 ACKNOWLEDGE the alarm at the DTAM.

5.8 .16 RECORD the manometer pressure and the DTAM water level readings.

Pressure on manometer Water Level on DTAM

5.8.17 SLOWLY INCREASE the manometer pressure until the alarm clears on the DTAM. (This should occur at 15.5 " $+/-0.5$ " water gauge.)

5.8 .18 RECORD the manometer pressure and the DTAM water level readings.

Pressure on manometer Water Level on DTAM ENSURE the "PIC Water" alarm indicates "norm".

5.8 .20 REMOVE the test manometer from the LT-6003T high pressure vent/test port and reinstall the vent plugs on both the high and low sides.

5.8.21___ OPEN valve V-6029T located in the Water Cabinet.

5.8.22__ OPEN valve V-6031T located in the Water Cabinet.

5.8.23___ ENSURE "Water Tank" reading on the DTAM shows a value in inches. Record the reading

\section{WEIGHT FACTOR TEST}

5.8.24_CONNECT a test manometer pressure source that can output at least 125 " water gauge to the HIGH PRESSURE dip tube on the side of the WFIE Cabinet. ENSURE V-6001T is CLOSED.

5.8 .26 ENSURE V-6005T is OPEN. 
RPP-6197

REVISION 0

5.8 .27 ENSURE V-6006T is OPEN.

5.8 .28 are CLOSED.

5.8.29 ENSURE the LOW and HIGH side isolation valves located on the V6036T 3-Valve manifold in the WFIE cabinet are OPEN.

5.8.30_ENSURE the EQUALIZING valve located on the V-6036T 3-Valve manifold in the WFIE cabinet is CLOSED.

5.8.31_ SET the test manometer to $125^{\prime \prime}(+/-1 ")$ water gauge. Record the manometer reading.

5.8.32 RECORD the "WFT" reading on the DTAM. The reading is to be 125" $\left(+/-5^{\prime \prime}\right)$.

5.8.33 _ BLEED off the pressure on the test manometer. Leave connected for testing the specific gravity transmitter. CLOSE V-6006T.

5.8.35_OPEN the EQUALIZING valve located on V-6036T 3-Valve manifold in the WFIE cabinet.

5.8.36 CLOSE the LOW and HIGH side isolation valves located on the V6036T 3-Valve manifold in the WFIE cabinet.

\section{SPECIFIC GRAVITY TRANSMITTER}

5.8 .37 ENSURE V-6007T is OPEN.

5.8 .38 ENSURE V-6005T is OPEN.

5.8.39 ENSURE the LOW and HIGH side isolation valves located on V-6035T 3-Valve manifold in the WFIE cabinet are OPEN.

5.8.40_ENSURE the specific gravity transmitter equalizing valve located on the V-6035T 3-Valve manifold located in the WFIE cabinet is CLOSED.

5.8.41___ SET the test manometer to 5 "water gauge (+/- 0.3").

5.8.42 RECORD the "SGT" reading on the DTAM. Reading to be 5" $+/-$ $0.35^{\prime \prime}$. 
RPP-6197

REVISION 0

5.8.43_ BLEED off pressure on the manometer.

5.8.44_ENSURE "SGT LOW” alarm occurs (alarm 13).

5.8.45_ACKNOWLEDGE the alarm.

5.8.46_ DISCONNECT the test manometer.

5.8.47_CLOSE V-6007T.

5.8.48_CLOSE V-6005T.

5.8.49___ OPEN the EQUALIZING valve located on V-6035T 3-Valve manifold in the WFIE cabinet.

5.8.50 CLOSE the LOW side and HIGH side isolation valves located on V6035T 3-Vaive manifold in the WFIE cabinet.

\section{FLOW METER SIGNAL CHECK}

5.8.51_Prepare the flow converter FQIT-6001T located in the Instrument Enclosure to simulate a flow either using the buttons on the front face or using a "brain terminal".

5.8.52 SIMULATE a flow signal of 7.0gpm (50\% span) with the hand-held brain terminal or from the flow converter face switches.

5.8.53_RECORD the flow readings on the front of the flow converter and on the DTAM (PMP FLOW). Readings to be $7.0+/-0.4 \mathrm{gpm}$.

Flow converter DTAM (PMP FLOW)

5.8.54_RESTORE the flow converter, FQIT-6001T to its original configuration. 


\section{SUCTION AND DISCHARGE PRESSURE SIGNAL}

5.8.55_ENSURE a current source is connected to PSPT + and PSPT- on the intrinsic side terminal board in the Intrinsic Safe panel. Set the source to "transmitter simulate."

5.8.56___ SET the current source to approximately $4 \mathrm{~mA}$ and record the suction pressure reading on PI-6012T. Reading to be approximately zero. psi

5.8.57__ SET the current source to approximately $20 \mathrm{~mA}$ and record the suction pressure reading on PI-6012T. Reading to be approximately $100 \mathrm{psi}$. psi

5.8 .58 DISCONNECT the current source.

5.8.59_ENSURE a current source is connected to PDPT+ and PDPT- at the intrinsic side terminal board in the Intrinsic Safe panel. Set the source to transmitter simulate.

5.8 .60 SET the current source to approximately $4 \mathrm{~mA}$ and record the discharge pressures on PI-6011T and on the DTAM. Readings should be approximately zero.

PI-6011T psi DTAM (PMP DISC) psi

5.8.61_SET the current source to approximately $20 \mathrm{~mA}$ and record the discharge pressures on PI-6011T and on the DTAM. Readings should be approximately $300 \mathrm{psi}$.

PI-6011T psi DTAM (PMP DISC) psi DISCONNECT the current source.

\section{COMBUSTIBLE GAS MONITOR ANALOG SIGNAL TO PLC}

5.8.63 ENSURE a current source is connected to the CGM loop by lifting the CGM $O(+)$ wire going to the CGM transmitter at terminal board TB1 in the Instrument Enclosure, and connecting the current source between CGM $0(+)$ at $\mathrm{TB} 1$ and the lifted $\mathrm{CGM} O(+)$ wire. 
5.8.65_RECORD the "CGM" percent reading from the DTAM. Reading is to be approximately zero. $\%$ SET the current source to approximately $12 \mathrm{~mA}$.

5.8.67_ RECORD the "CGM" percent reading from the DTAM. Reading is to be approximately $50 \%$. $\%$

5.8.68_ SET the current source to approximately $20 \mathrm{~mA}$.

5.8.69_RECORD the "CGM" percent reading from the DTAM. Reading is to be approximately $100 \%$. $\%$

5.8.70_DISCONNECT the current source and reconnect the CGM $0(+)$ wire to TB1.

\section{DOME SPACE FLAMMABLE GAS MONITOR ANALOG SIGNAL TO PLC}

5.8.71_ENSURE a current source is connected to terminal board TB1 in the Instrument Enclosure, points FGM 1(+) and FGM 1(-)

5.8.72__ SET the current source to approximately $4 \mathrm{~mA}$.

5.8.73 RECORD the "FGM" percent reading from the DTAM. Reading is to be approximately zero. $\%$

5.8.74___ SET the current source to approximately $12 \mathrm{~mA}$.

5.8.75_RECORD the "FGM" percent reading from the DTAM. Reading is to be approximately $50 \%$. $\%$

5.8.76___ SET the current source to approximately $20 \mathrm{~mA}$.

5.8.77_ RECORD the "FGM" percent reading from the DTAM. Reading is to be approximately $100 \%$. $\%$

5.8 .78 DISCONNECT the current source.

\section{THERMOCOUPLE INPUTS TO THE PLC}

5.8 .79 WARM thermocouple TE-6004T located in the Instrument Enclosure. 

change.

ENSURE the "PLC CAB temp" on the DTAM displays a temperature

5.8.81 CONTINUE to warm the thermocouple until "PLC Enclosure HI" (alarm 10) occurs. This will be approximately 130 degrees $F$. ACKNOWLEDGE the alarm.

5.8.83 ENSURE "PLC CAB temp" on the DTAM shows a temperature DECREASE after the heat source is removed from the TE-6004T thermocouple.

5.8.84_ENSURE the "PLC temp" alarm returns to "norm" when the temperature decreases below 125 degrees $\mathrm{F}$.

5.8.85_WARM thermocouple TE-6003T located in the Air Compressor Cabinet.

5.8.86_ENSURE the "COMPRS temp" on the DTAM displays a temperature change.

5.8.87_CONTINUE to warm the thermocouple until "Air Compressor Temp HI" (alarm 11) occurs. This will be approximately 130 degrees F. ACKNOWLEDGE the alarm.

5.8.89_ENSURE “COMPRS temp" on the DTAM shows a temperature DECREASE after the heat source is removed from the TE-6003T thermocouple.

5.8.90_ENSURE the "CMPRSR temp" alarm returns to "norm" when the temperature decreases below 125 degrees $F$.

5.8.91 COOL the thermocouple probe in the WFIE cabinet using ice water or cool air spray. Temperature needs to drop below 35 degrees $\mathrm{F}$. ENSURE alarm 50, "WFIE CAB Temp Low" occurs at the DTAM. cabinet and ENSURE the "WFIE CAB Temp" alarm is "norm" when the temperature goes above 40 degrees $F$.

5.8.94_COOL the thermocouple probe in the Water cabinet using ice water or cool air spray. Temperature needs to drop below 35 degrees $F$.

5.8.95___ ENSURE alarm 49, "WATER CAB Temp Low" occurs at the DTAM. 

cabinet and ENSURE the "WATER CAB Temp" alarm is "norm" when the temperature goes above 40 degrees $\mathrm{F}$.

5.8.97_CONNECT two temperature simulators to the intrinsic side of the two thermocouple modules (MTL 3081) in the Intrinsic Safe panel.

SET the motor temperature alarm setpoints at the DTAM to 125 degrees $F$ for the high and 135 degrees $F$ for the high high. NOTE: The security code is 11 for the restricted screen for entry.

5.8.99___ SET both temperature simulators to approximately 120 degrees F.

5.8.100_ENSURE the "PUMP temp" and the "JMPER TEMP" each read approximately 120 degree at the DTAM. (Pump) (Jumper)

5.8 .101 ENSURE the "Jmp Htr" is ON at the DTAM.

5.8.102__ DECREASE the temperature simulator on the top module to approximately 39 degrees or lower until alarm 8 "Pump/Jumper Temp Trouble" alarms on the DTAM.

5.8 .103 ACKNOWLEDGE the alarm.

5.8 .104 DTAM.

ENSURE the "PUMP TEMP" reads approximately 39 degree at the

5.8.105_INCREASE the temperature simulator on the top module to approximately 120 degrees.

5.8.106_ENSURE the "JMPR HT" alarm on the DTAM reads "norm".

5.8.107_ENSURE the "Jmp Htr" is ON at the DTAM.

5.8.108___ENSURE the switches installed on TB4 between points "CGM-AX" and "CKT5H-A"; and "CGM-F" and "CKT5H-A" are in the CLOSED position.

5.8 .109 ENSURE approximately 120vac between HT-1 and CKT3-N at TB12. vac

5.8.110_WHILE MONITORING the voltage at TB12, INCREASE the temperature on the second module to 206 degrees $F$ or higher until the voltage at TB12 goes to approximately zero. DTAM temp. 
5.8.111___ WHILE MONITORING the voltage at TB12, decrease the temperature on the second module to 194 degrees $F$ or lower until the voltage at TB12 goes to approximately $120 \mathrm{vac}$. DTAM temp.

5.8.112_ OPEN the switch on TB4 that is across "CGM-AX" and "CKT5H-A".

5.8.113___ENSURE alarm "25" occurs and ACKNOWLEDGE.

5.8.114___ ENSURE the voltage at TB12 goes to approximately zero.

5.8.115_CLOSE the switch on TB4 that is across "CGM-AX" and "CKT5H-A".

5.8.116_ENSURE the voltage at TB12 returns to approximately $120 \mathrm{vac}$.

5.8.117_OPEN the switch on TB4 that is across "CGM-F" and "CKT5H-A".

5.8.118_ENSURE alarm " 31 " occurs and ACKNOWLEDGE.

5.8.119____ENSURE the voltage at TB12 goes to approximately zero.

5.8.120_CLOSE the switch on TB4 that is across "CGM-F" and "CKT5H-A".

5.8.121_ENSURE the voltage at TB12 returns to approximately $120 \mathrm{vac}$.

5.8.122_TURN OFF the heat trace from the DTAM.

5.8.123_ENSURE the voltage at TB12 goes to approximately zero.

5.8.124_ TURN ON the heat trace from the DTAM.

5.8.125_ENSURE the voltage at TB12 returns to approximately $120 \mathrm{vac}$.

5.8.126_INCREASE the temperature simulator on the second module to approximately 226 degrees or higher until alarm 8 "Pump/Jumper Temp Trouble" alarms on the DTAM.

5.8.127_ACKNOWLEDGE the alarm.

5.8.128_ DECREASE the temperature simulator on the second module to less than 225 degrees.

5.8.129_ENSURE the "JMPR HT" alarm 8 returns to "norm" on the DTAM.

5.8.130_ REMOVE the temperature simulator from the bottom module, but leave the top temperature simulator connected for the interlock checks in section 5.9 . 
RPP-6197

REVISION 0

5.8.131Engineer to Ensure section 5.8 is completed and sign below.

Engineer Signature Date

5.8.132Quality Assurance Inspector to Verify that section 5.8 is complete and sign below.

Quality Assurance Inspector Signature Date 
RPP-6197

REVISION 0

\subsection{JET PUMP INTERLOCK CIRCUITS}

5.9.1 ENSURE the LS-1 and LS-2 proximity switches at the Intrinsic safe panel; the two leak detector probes; the two CGM, the Dilution, and the AX101 switches at TB4 in the Instrument Enclosure are in place as per steps 5.8.1 to 5.8.6.

5.9.2 IF POSSIBLE, CONNECT three current sources to the following points. One to JFPT + and JFPT-in the Intrinsic Safe panel at the intrinsic terminal board; one to RFPT + and RFPT- in the Instrument Enclosure at TB2; and one to PXPT+ and PXPT- at the intrinsic terminal board in the Intrinsic safe panel. Set the current sources to "transmitter simulate" and at $6 \mathrm{~mA}$. NOTE: If three current sources are not available, then software forces will be used during this section to bypass the inputs not being tested.

5.9.3 SET the temperature simulator at the Intrinsic Safe panel to 120 degrees F.

5.9.4 ENSURE the temperature setpoint for the motor-bearing temperature high-alarm is set to 125 degrees $\mathrm{F}$ and the high-high-alarm is set to 135 degrees F.

5.9.5 CONNECT the laptop computer to the PLC to set forces and observe logic when required.

5.9.6 RECORD the reading of the Hourmeter on the front of the Instrument Enclosure.

\section{RECIRCULATION FLUSH PRESSURE SIGNAL TO PLC}

5.9.7 ENSURE a current source is connected to points RFPT+ and RFPT- in the Instrument Enclosure at TB2 and is set to approximately $6 \mathrm{~mA}$.

5.9.8 ENSURE the green light on the Instrument Enclosure and on the Jet Pump motor starter are ON.

5.9.9 APPLY software forces to allow the jet pump to start. (Engineering will apply the forces from the laptop computer connected to the PLC. Normally this will be the COMM Failure and any leak station interlocks. These can be forced out by setting the timers to a high set value such as 7200 seconds with the laptop on-line. If the timers need to be reset to start counting, this is done by turning the key switch on the PLC from "RUN" to "PROGRAM" and then back to "RUN".) TURN the selector switch on the Jet Pump Motor Starter to ON. 
5.9.11_ START the jet pump from the DTAM and OBSERVE that the red lights at the Instrument Enclosure and motor starter come $\mathrm{ON}$ and the green lights at both locations turn OFF.

5.9.12_SLOWLY INCREASE the current source output to approximately $12.5 \mathrm{~mA}$ or until the pump shuts down after a 3 second delay. OBSERVE the following: (Acknowledge the alarms as necessary to observe all the alarms.) NOTE: The horn sound can be adjusted by turning the set screw on the front of the horn for sound level as directed by the engineer or PIC.

Record current reading on current source. $\mathrm{mA}$ The strobe light flashes and the horn sounds. Alarm 12 occurs, "JET PUMP SHUTDOWN". Alarm 39 occurs, "RECIRC FLUSH PRESS HI". Red lights at the motor starter and Instrument Enclosure are OFF. Green lights at the motor starter and Instrument Enclosure are ON. The "RECR FL PR" is approximately $15 \mathrm{psi}$. psi

Ensure addresses N20:32/2 and N20:32/6 are actuated as observed on the laptop computer in ladder 5 .

5.9 .13 DECREASE the current source to approximately $4 \mathrm{~mA}$.

5.9 .14 ENSURE the "Recirc Press" alarm at the DTAM returns to "norm". ENSURE address N20:32/6 clears as observed on the laptop.

5.9.16 START the jet pump from the DTAM and OBSERVE that the red lights at the Instrument Enclosure and motor starter come $\mathrm{ON}$ and the green lights at both locations turn OFF. DECREASE the current source to zero.

5.9 .18 ENSURE the jet pump shuts down.

5.9 .19 ENSURE alarm 14, "RFPT SIGNAL LOSS ALARM" occurs. ACKNOWLEDGE the alarm.

5.9 .21 ENSURE address N20:32/7 is actuated as observed on the laptop.

5.9.22 INCREASE the current source to approximately $6 \mathrm{~mA}$.

5.9.23 EN__ENSE the "RFPT SIGNAL" alarm returns to "norm" on the DTAM. 5.9.24_ENSURE address N20:32/7 clears as observed on the laptop. 


\section{JUMPER FLUSH PRESSURE SIGNAL TO PLC}

5.9.25_ENSURE a current source is connected to points JFPT+ and JFPT- in the Intrinsic Safe panel intrinsic terminal board and is set to approximately $6 \mathrm{~mA}$.

5.9.26 ENSURE the green light on the Instrument Enclosure and on the Jet Pump motor starter are ON.

5.9.27 APPLY software forces as necessary to allow the jet pump to start. (Engineering will apply the forces from the laptop computer connected to the PLC.)

5.9.28_START the jet pump from the DTAM and OBSERVE that the red lights at the Instrument Enclosure and motor starter come $O N$ and the green lights at both locations turn OFF.

5.9.29___ENSURE address N20:32/2 is clear as observed on the laptop.

5.9.30_ SLOWLY INCREASE the current source output to approximately $12.5 \mathrm{~mA}$ or until the pump shuts down after a 3 second delay. OBSERVE the following: (Acknowledge the alarms as necessary to observe all the alarms.)

The jet pump shuts down.

Record current reading on current source. $\mathrm{mA}$ Alarm 3 occurs, "Flush Pressure HI". Alarm 12 occurs, "JET PUMP SHUTDOWN". Blue light at the Instrument Enclosure is ON. The "PS2 FL PR" is approximately $15 \mathrm{psi}$. psi Ensure address N20:32/5 is actuated as observed on the laptop. DECREASE the current source to approximately $4 \mathrm{~mA}$.

5.9 .32 ENSURE the "Flush Press" alarm at the DTAM returns to "norm".

5.9.33___ ENSURE the blue light at the Instrument Enclosure turns OFF.

5.9.34_ENSURE address N20:32/5 clears as observed on the laptop.

5.9.35___ START the jet pump from the DTAM.

5.9.36___ DECREASE the current source to zero.

5.9.37___ENSURE the jet pump shuts down.

5.9.38__ ENSURE alarm 16, “JFPT SIGNAL LOSS ALARM” occurs. 

ACKNOWLEDGE the alarm.

5.9 .40 ENSURE address N20:32/8 actuates as observed on the laptop.

5.9 .41 INCREASE the current source to approximately $6 \mathrm{~mA}$.

5.9 .42 ENSURE the "JFPT SIGNAL" alarm returns to "norm" on the DTAM.

5.9 .43 ENSURE address N20:32/8 clears as observed on the laptop.

\section{TRANSFER PRESSURE INTERLOCK INPUT}

5.9.44 ENSURE a current source is connected to points PXPT+ and PXPT- in the Intrinsic Safe panel intrinsic terminal board and is set to approximately $6 \mathrm{~mA}$.

5.9.45 ENSURE the laptop computer is connected to the PLC and is "on-line".

5.9.46_ENSURE the green light on the Instrument Enclosure and on the Jet Pump motor starter are ON.

5.9.47_APPLY software forces to allow the jet pump to start. (Engineering will apply the forces from the laptop computer connected to the PLC.)

5.9.48__ START the jet pump from the DTAM.

5.9.49 DECREASE the current source to approximately $4.8 \mathrm{~mA}$ or until Timer 4.1 on the ladder logic of the PLC (rung 0 of ladder 5) starts timing.

5.9.50 ENSURE the amber light on the Instrument Enclosure turns ON immediately after the timer starts.

5.9.51_ENSURE after 30 seconds, the following occurs: (Acknowledge alarms as necessary to view all the alarms.)

The jet pump shuts down.

"XFR Pressure LOW" (alarm 1) occurs at the DTAM.

"JET PUMP SHUTDOWN" (alarm12) occurs at the DTAM.

INCREASE the current source to approximately $6 \mathrm{~mA}$. ENSURE the "XFR Pressure" alarm is "norm" on the DTAM. START the pump from the DTAM. 
5.9.55_INCREASE the current source to approximately $11.5 \mathrm{~mA}$ or until Timer 4.2 on rung 2 of ladder 5 starts timing as observed on the laptop computer.

5.9.56 ENSURE after a 3 second delay, the following occurs: (Acknowledge alarms as necessary to view all the alarms.)

The jet pump shuts down.

"XFR Pressure HIGH" (alarm 2) occurs at the DTAM.

"JET PUMP SHUTDOWN" (alarm12) occurs at the DTAM.

5.9 .57 DECREASE the current source to approximately $6 \mathrm{~mA}$.

5.9 .58 ENSURE the "XFR Pressure" alarm indicates "norm" on the DTAM.

\section{JR-1 VALVE POSITION INPUT (LS-1 AND LS-2)}

5.9.59__ START the pump from the DTAM.

5.9.60__ REMOVE the metal from the front face of LS-1.

5.9.61___ENSURE the following occurs immediately: (Acknowledge alarms as necessary to view all the alarms.)

The jet pump shuts down.

"JR-1 Position NON-PROCESS" (alarm 5) occurs at the DTAM. "JET PUMP SHUTDOWN" (alarm12) occurs at the DTAM.

Address N20:32/0 on ladder 5 is actuated as observed on the laptop.

5.9 .62

REMOVE the metal form the front face of LS-2.

5.9 .63 ENSURE the "JR-1" still indicates "NON-PROCESS" at the DTAM.

5.9.64 ENSURE address N20:32/1 is actuated on ladder 5 as observed on the laptop.

5.9 .65 REPLACE the metal in front of LS-1 and LS-2.

5.9.66 ENSURE the "JR-1" indicates "norm" on the DTAM and addresses N20:32/0 and N20:32/1 are clear on ladder 5 as observed on the laptop.

\section{COMBUSTIBLE GAS MONITOR INTERLOCK INPUTS}

5.9 .67 START the pump from the DTAM.

5.9 .68 OPEN the CGM-AX switch at TB4. 


\section{RPP-6197 \\ REVISION 0}

5.9.69_ENSURE the following occurs immediately: (Acknowledge alarms as necessary to view the alarms.)

The jet pump shuts down.

"JET PUMP SHUTDOWN" (alarm12) occurs at the DTAM.

"HIGH LFL ON CGM" (alarm 25) occurs at the DTAM.

5.9.70__ CLOSE the CGM-AX switch at TB4.

5.9.71___ ENSURE the "HI LFL CGM" alarm indicates "norm" at the DTAM.

5.9.72___ START the pump from the DTAM.

5.9.73__ OPEN the CGM-F switch at TB4.

5.9.74_ENSURE the following occurs after a 3-second delay: (Acknowledge alarms as necessary to view the alarms.)

The jet pump shuts down.

"JET PUMP SHUTDOWN" (alarm12) occurs at the DTAM.

"CGM TROUBLE" (alarm 31) occurs at the DTAM.

5.9.75_CLOSE the CGM-F switch at TB4.

5.9.76 ENSURE the "CGM TROUBLE" alarm indicates "norm" at the DTAM.

5.9.77___ START the pump from the DTAM.

5.9.78___ OPEN the dilution switch at TB4 in the Instrument Enclosure.

5.9.79_ENSURE the following occurs after a 5-minute delay: (Acknowledge alarms as necessary to view the alarms.)

The jet pump shuts down.

"JET PUMP SHUTDOWN" (alarm12) occurs at the DTAM.

"DILUTION TANK NO FLOW" (alarm 35) occurs at the DTAM.

5.9 .80 CLOSE the dilution switch.

5.9.81_ENSURE the "Dilution tk" alarm indicates "norm" on the DTAM.

\section{MOTOR HIGH TEMPERATURE}

5.9 .82 START the pump from the DTAM. 


\section{RPP-6197 \\ REVISION 0}

5.9.83 INCREASE the temperature on the temperature simulator to approximately 126 degrees F or greater until alarm 58, "MOTOR TEMP HIGH" actuates.

5.9.84_INCREASE the temperature on the temperature simulator to approximately 136 degrees $\mathrm{F}$ or greater until the following occurs:

The jet pump shuts down.

"JET PUMP SHUTDOWN" (alarm12) occurs at the DTAM.

"Motor Temp Hi Shutdown" (alarm 59) occurs at the DTAM.

5.9.85_DECREASE the temperature simulator to approximately 125 degrees $F$ or lower until alarm "PMP HIHI TEMP" indicates "norm" at the DTAM.

5.9.86_ENSURE the "PMP HI TEMP" alarm indicates "norm" at the DTAM.

\section{LEAK DETECTION INTERLOCK}

5.9.87 ENSURE there is a water supply and bucket available to actuate the leak detector probes.

5.9.88__ START the pump from the DTAM.

5.9.89_ PLACE the primary leak detector probe in a bucket of water.

5.9.90____ENSURE the following occurs after a 3-second delay: (Acknowledge alarms as necessary to view the alarms.)

The jet pump shuts down.

"PUMP PIT LEAK" (alarm 6) occurs at the DTAM.

"JET PUMP SHUTDOWN" (alarm12) occurs at the DTAM. Enclosure.

The red light for the "Primary" leak detector is ON at the Instrument

Ensure address N20:32/3 in ladder 5 actuates as observed on the laptop.

5.9.91_REMOVE the leak detector probe from the bucket and allow the water to drain off.

5.9.92 ___ ENSURE the "Pump Pit" leak alarm returns to "norm".

5.9.93_ENSURE the red light for the "Primary" leak detector is OFF.

5.9.94___ ENSURE address N20:32/3 clears as observed on the laptop.

5.9.95_ START the pump from the DTAM. 
DISCONNECT one of the "SD" wires going to the primary leak detector probe.

5.9.97__ENSURE the following occurs after a 3-second delay: (Acknowledge alarms as necessary to view the alarms.)

The jet pump shuts down. "PUMP PIT LEAK TROUBLE" (alarm 7) occurs at the DTAM. "JET PUMP SHUTDOWN" (alarm12) occurs at the DTAM. The red light for the "Primary" leak detector at the Instrument Enclosure is $\mathrm{ON}$.

Ensure address N20:32/3 actuates as observed on the laptop. RECONNECT the "SD" wire.

5.9.99 ENSURE the "Pump Pit" trouble alarm indicates "norm" on the DTAM.

5.9.100__ ENSURE the red light for the "Primary" leak detector is OFF.

5.9.101___ ENSURE address N20:32/3 clears as observed on the laptop.

5.9.102__ START the pump from the DTAM.

5.9.103__ PLACE the leak detector 1 probe in a bucket of water.

5.9.104_ENSURE the following occurs after a 3-second delay: (Acknowledge alarms as necessary to view the alarms.)

The jet pump shuts down.

"JET PUMP SHUTDOWN" (alarm12) occurs at the DTAM. the DTAM.

"LEAK DETECTOR NO 1 LEAK DETECTED" (alarm 18) occurs at

The red light for "Leak Detector 1" at the Instrument Enclosure is ON. Ensure address N20:32/4 actuates in ladder 5 as observed on the laptop.

5.9.105_ REMOVE the leak detector probe from the bucket and allow the water to drain off.

5.9.106___ENSURE the "Leak 1" alarm returns to "norm".

5.9.107___ENSURE the red light for "Leak Detector 1" is OFF.

5.9.108___ ENSURE address N20:32/4 clears as observed on the laptop. 
RPP-6197

REVISION 0

5.9.109___ START the pump from the DTAM.

5.9.110_ DISCONNECT one of the "SD" wires going to the leak detector 1 probe.

5.9.11____ENSURE the following occurs after a 3-second delay: (Acknowledge alarms as necessary to view the alarms.)

The jet pump shuts down.

"JET PUMP SHUTDOWN" (alarm12) occurs at the DTAM. DTAM.

"LEAK DETECTOR NO 1 TROUBLE" (alarm 19) occurs at the

The red light for "Leak Detector 1" at the Instrument Enclosure is ON.

Ensure address N20:32/4 actuates as observed by the laptop.

5.9 .112

RECONNECT the "SD" wire.

5.9.113_ENSURE the "Leak 1 ck" alarm indicates "norm" on the DTAM.

5.9.114_ENSURE the red light for "Leak Detector 1" is OFF.

5.9.115___ ENSURE address N20:32/4 clears as observed on the laptop.

5.9.116__ RECORD the hourmeter reading.

5.9.117_ VERIFY by comparing the readings in steps 5.9.6 and 5.9.108 that the hourmeter is recording time.

5.9.118_ REMOVE the software forces and disconnect the laptop computer from the PLC.

5.9.119__ TURN OFF breakers $2,3,5$, and 6 in the distribution panel.

5.9.120_DISCONNECT the current sources from the PXPT, RFPT and JFPT termination points.

5.9.121__ DISCONNECT the test switches from the CGM, FGM, and Dilution termination points.

5.9.122_DISCONNECT the proximity switches from the Intrinsic Safe panel.

5.9.123_ DISCONNECT the leak detector probes from the Instrument Enclosure.

5.9.124__ TURN ON breakers $2,3,5$, and 6 at the distribution panel. 
RPP-6197

REVISION 0

5.9.125Engineer to ENSURE section 5.9 is completed and sign below.

Engineer Signature Date

5.9.126Quality Assurance Inspector to VERIFY that section 5.9 is completed and sign below.

Quality Assurance Inspector Signature

Date 


\subsection{HEATERS, AIR CONDITIONER AND LIGHTS}

5.10.1 TURN the heater ON in the air compressor cabinet. Set the thermostat high enough to allow the unit to operate.

5.10.2_ RESET the thermostat to approximately 40 degrees $F$ to allow the heat to turn OFF. Then unplug the heater.

5.10.3_TURN the fan thermostat switch to allow the fan in the air compressor cabinet to run.

5.10.4__ RESET the fan switch to approximately 90 degrees $F$ to allow the fan to turn OFF.

5.10.5_TURN the heater ON in the WFIE cabinet. Set the thermostat high enough to allow the unit to operate.

5.10.6___ RESET the thermostat to approximately 40 degrees $F$ to allow the heat to turn OFF. Then unplug the heater.

5.10.7 TURN the heater ON in the Water cabinet. Set the thermostat high enough to allow the unit to operate.

5.10.8_RESET the thermostat to near the "LO" setting to allow the heat to turn $\overline{\mathrm{OFF}}$. Then unplug the heater.

5.10.9 TURN the heater ON in the Instrument Enclosure. Set the thermostat high enough to allow the unit to operate.

5.10.10__ RESET the thermostat to approximately 40 degrees $F$ to allow the heat to turn OFF. Then unplug the heater.

5.10.11_ TURN the heater ON in the Locker. Set the thermostat high enough to allow the unit to operate.

5.10.12_ RESET the thermostat to approximately 40 degrees $F$ to allow the heat to turn OFF. Then unplug the heater.

5.10.13_ TURN ON the air conditioner in the Instrument Enclosure. If necessary, remove the front grill on the unit and adjust the temperature setting to get the unit to operate.

5.10.14_ RESET the temperature setting on the air conditioner to between 90 to 95 degrees $F$. Remove the grill and filter on the front of the air conditioner for access to the adjustment. Then unplug the air conditioner. 
RPP-6197

REVISION 0

5.10.15___ENSURE the light in the WFIE cabinet operates.

5.10.16___ ENSURE the light in the Instrument Enclosure operates.

5.10.17Engineer to ENSURE that section 5.10 is completed and sign below.

Engineer Signature Date

5.10.18Quality Assurance Inspector to VERIFY that section 5.10 is completed and sign below.

Quality Assurance Inspector Signature

Date 


\subsection{SKID PREPARATION FOR SHIPPING}

5.11.1. Ensure the following PIC skid circuit disconnects, breakers and fuses are OPEN or OFF.

$\begin{array}{r}\text { DS-6002T } \\ \text { DS-6003T } \\ \hline \text { DS-6004T } \\ \hline \text { DS-6005T }\end{array}$

The breakers below are located in the distribution panel DP-6001T:

\begin{tabular}{c} 
Breaker "MAIN" \\
Breaker 1 \\
Breaker 3 \\
Breaker 5 \\
Breaker 7 \\
Breaker 9 \\
Breaker 11 \\
\hline Breaker 13
\end{tabular}

Breaker 2 Breaker 4 Breaker 6 Breaker 8 Breaker 10 Breaker 12 Breaker 14

5.11.2. Disconnect the power plug from the 480vac power source.

5.11.3. Bleed the air pressure off the air system by OPENING the following valves:

$\begin{array}{r}\text { V-6043T } \\ \text { V-6046T } \\ \hline \text { V-6047T } \\ \hline \mathrm{V}-6037 \mathrm{~T}\end{array}$

NOTE: After the air system has bled down, proceed with the following valve positioning.

5.11.4. Ensure the following PIC skid valves in the WFIE cabinet are OPEN. V-6035T (EQUALIZING) V-6036T (EQUALIZING) 


\section{RPP-6197 \\ REVISION 0}

5.11.5. E___Ensure the following valves are CLOSED.
Air Compressor
Water Cabinet
\begin{tabular}{r}
$\mathrm{V}-6025 \mathrm{~T}$ \\
$\mathrm{~V}-6026 \mathrm{~T}$ \\
$\mathrm{~V}-6034 \mathrm{~T}$ \\
$\mathrm{~V}-6043 \mathrm{~T}$ \\
$\mathrm{~V}-6044 \mathrm{~T}$ \\
$\mathrm{~V}-6046 \mathrm{~T}$ \\
$\mathrm{~V}-6047 \mathrm{~T}$ \\
$\mathrm{~V}-6048 \mathrm{~T}$ \\
$\mathrm{~V}-6049 \mathrm{~T}$ \\
\hline $\mathrm{V}-6050 \mathrm{~T}$ \\
\hline $\mathrm{V}-6051 \mathrm{~T}$ \\
$\mathrm{~V}-6053 \mathrm{~T}$
\end{tabular}
V-6027T
$\mathrm{V}-6029 \mathrm{~T}$
V-6030T
$\mathrm{V}-6031 \mathrm{~T}$
V-6032T
V-6037T
V-6052T
WFIE Cabinet

\begin{tabular}{r}
$\mathrm{V}-6001 \mathrm{~T}$ \\
$\mathrm{~V}-6002 \mathrm{~T}$ \\
$\mathrm{~V}-6003 \mathrm{~T}$ \\
$\mathrm{~V}-6004 \mathrm{~T}$ \\
$\mathrm{~V}-6005 \mathrm{~T}$ \\
$\mathrm{~V}-6006 \mathrm{~T}$ \\
$\mathrm{~V}-6007 \mathrm{~T}$ \\
$\mathrm{~V}-6008 \mathrm{~T}$ \\
\hline $\mathrm{V}-6011 \mathrm{~T}$ \\
\hline $\mathrm{V}-6012 \mathrm{~T}$ \\
\hline $\mathrm{V}-6013 \mathrm{~T}$ \\
$\mathrm{~V}-6014 \mathrm{~T}$
\end{tabular}

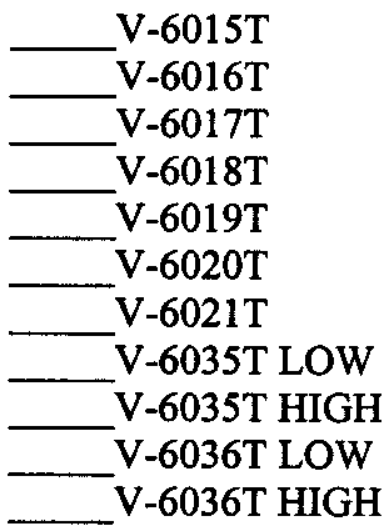

5.11.6. ENSURE the power plug on the power cable is a Crouse-Hinds model APJ3475.

5.11.7 Engineer to ENSURE that section 5.11 is completed and sign below.

Engineer Signature Date

5.11.8. Quality Assurance Inspector to VERIFY that section 5.11 is completed and sign below. 


\section{RPP-6197 \\ REVISION 0 \\ ACCEPTANCE TEST PROCEDURE}

This page may be reproduced as necessary

PAGE of

\begin{tabular}{|c|c|c|}
\hline \multicolumn{3}{|c|}{ ACCEPTANCE TEST PROCEDURE LOG } \\
\hline Name & Date & Comment \\
\hline & & \\
\hline & & \\
\hline & & \\
\hline & & \\
\hline & & \\
\hline & & \\
\hline & & \\
\hline & & \\
\hline & & \\
\hline & & \\
\hline & & \\
\hline & & \\
\hline & & \\
\hline & & \\
\hline
\end{tabular}


RPP-6197

REVISION 0

\section{ACCEPTANCE TEST PROCEDURE EXCEPTION LOG}

This page may be reproduced as necessary of

\section{ACCEPTANCE TEST PROCEDURE EXCEPTION LOG}

\begin{tabular}{|c|c|c|}
\hline Number & Date & Description \\
\hline & & \\
\hline & & \\
\hline & & \\
\hline & & \\
\hline & & \\
\hline & & \\
\hline & & \\
\hline & & \\
\hline & & \\
\hline & & \\
\hline & & \\
\hline & & \\
\hline & & \\
\hline & & \\
\hline & & \\
\hline
\end{tabular}




\section{ACCEPTANCE TEST PROCEDURE EXCEPTION RECORD}

This page may be reproduced as necessary.

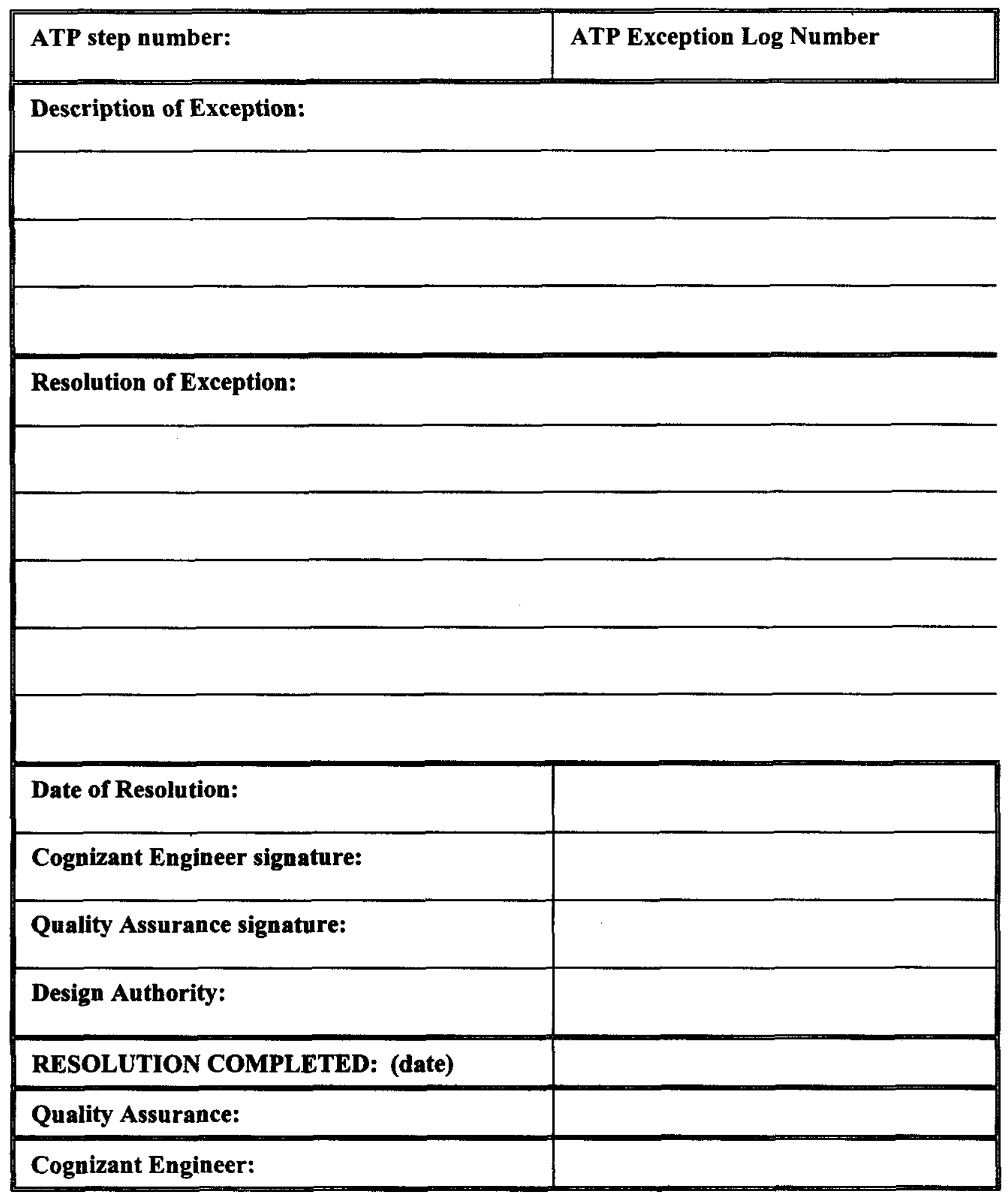


RPP-6197

REVISION 0

\section{ACCEPTANCE TEST PROCEDURE ACCEPTANCE RECORD}

Section 5.0 of the Acceptance Test Procedure has been completed including completion of all exceptions. The test results are accepted by the undersigned:

Cognizant Engineer (Signature)

(Print Name)

Date

Quality Assurance (Signature)

(Print Name)

Date 


\section{RPP-6197 \\ REVISION 0 \\ PROCEDURE PERFORMER SIGNATURE SHEET}

All personnel who will be performing, initialing and signing the procedure shall enter their printed name, signature and initials below.

\begin{tabular}{|c|c|c|}
\hline PRINT NAME & SIGNATURE & INITIALS \\
\hline & & \\
\hline & & \\
\hline & & \\
\hline & & \\
\hline & & \\
\hline & & \\
\hline & & \\
\hline & & \\
\hline & & \\
\hline & & \\
\hline & & \\
\hline & & \\
\hline & & \\
\hline & & \\
\hline & & \\
\hline & & \\
\hline & & \\
\hline & & \\
\hline & & \\
\hline
\end{tabular}


RPP-6197

REVISION 0

\section{PRE-JOB BRIEF SIGNATURE PAGE}

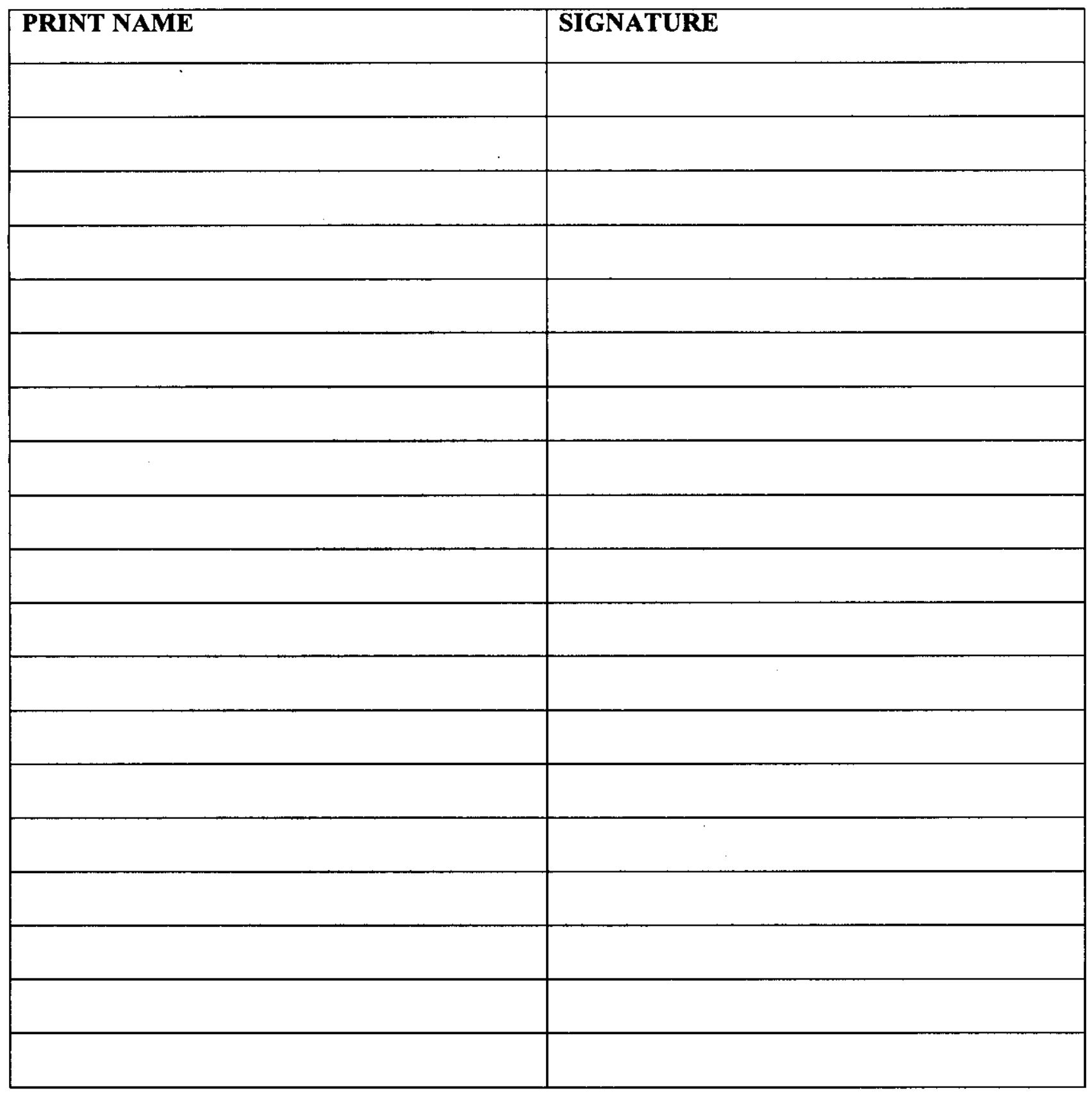

